\title{
LA PHYSICA EN LOS ARISTOTÉLICOS DEL SIGLO XVI
}

\author{
Bartomeu Forteza Pujol
}

SÍNTESIS - 1. Anistotelismos y antiaristotelismo en los ss. XVI y XVII. Se dan en esta época dos aristotelismos en Italia (el averroismo paduano y el alejandrinismo) y otro en España (el propio de la llamada Segunda Escolástica). El antiaristotelismo conoce dos momentos fuertes. 2. La relación entre la Physica y la Metaphysica. Se discute entre los autores si la Filosofia Primera constituye una ciencia aparte, o si debe considerarse como una Physica Generalis, es decir, como la exposición de las definiciones primeras. 3. Tres modalidades: los Comentarios a Aristóteles: concebidos a la manera tradicional, pero caracterizados ya por un marcado eclecticismo; los Manuales: repeticiones de la Fisica que nacen a raíz de la instauración de la ratio studionum de los jesuitas; las obras sobre física escritas iuxta propria principia: investigaciones originales que, si bien no ocultan la lectura de Aristóteles, se apartan notablemente de su filosofía. 4. Tres conceptos básicos: espacio, tiempo y movimiento, en algunos autores significativos: Bernardino Telesio, Francesco Patrizi, los Coninbricenses, Benito Pereira y Francisco Suárez.

PALABRAS-CLAVE - Aristotelismo. Física y Metafísica. Comentarios a Aristoteles. Espácio. Tiempo. Movimiento.
ABSTRACT - 1. Aristotelianism and antiaristotelianism in the XVIth and the XVIIth centuries. Two forms of Aristotelianism apper at the time in Italy (Paduan Averroism and Alexandrianism) and another one in Spain (the one corresponding to the so called Second Scholastics), the Antiaristotelianism has two strong periods. 2. The relationship between the Physica and the Metaphysica it is discussed among authors whether the Prime Philosophy constitutes an independent science or must be considered as a Physica Generalis, that is to say, the exposition of prime definitions. 3 . Three modalities: commentanies on Aristotle: considered in the traditional way, yet characterized by an intense eclecticism; the Manuals: iteration of the Physics originated because of the instauration of the ratio studiorum of the Jesuits; the writings iuxta propria principia on Physics: original researches that even reflecting the reading of Aristotle, diverge considerably from his Philosophy. 4. Three basic concepts: space, time and movement in some meaningful authors: Bernardino Telesio, Francesco Patrizi, the Coninbricenses, Benito Pereira and Francisco Suárez. KEY WORDS - Aristotelism. Physics and Metaphysics. Commentaries on Aristotle. Space. Time. Motion.

Como es sabido, la physeos espistéme que Aristóteles habia desarrollado en ocho libros fue objeto de comentarios por parte de los más destacados maestros a lo largo de la Edad Media. Esta tradición no se interrumpe con la llegada del $\mathrm{Hu}-$ manismo y el Renacimiento europeos; más aún, debemos decir que queda fortalecida por dos factores: la lectura directa del texto aristotélico griego y el descubri-

\begin{tabular}{|l|l|l|l|l|l|}
\hline VERITAS & Porto Alegre & v. 44 & n. 3 & Setembro 1999 & p. 865-870 \\
\hline
\end{tabular}


miento y difusión de nuevos comentarios de algunos autores antiguos. Pero, mientras tanto, se ha multiplicado el interés por el estudio renovado de la naturaleza, la cual adquiere en algunos filósofos renacentistas un carácter numénico que conduce a la renovación del antiguo ideal contemplativo que animara veinte siglos antes al Estagirita.

Pero el panorama intelectual es complejo en el siglo XVI y la lectura de Aristóteles se hace de diversas maneras, como reflejo de la encrucijada entre un mundo caduco que se esfuerza en renovarse y un mundo nuevo que quiere afirmar su hegemonía. Veámoslo con más detenimiento.

\section{Aristotelismos y antiaristotelismo en el siglo XVI}

Charles B. Schmitt, una de las grandes autoridades en el estudio del Renacimiento, junto con Lohr, Garin, Kristeller..., escribía en el año 1983: “El Renacimiento es el periodo más descuidado por los históricos de la filosofía, y particularmente del aristotelismo... El periodo menos estudiado en la historia de la filosofía - y de la ciencia - es el que separa Ockham y Oresme de Galileo y Descartes". Sin duda, el acerbo historiográfico y los estudios en profundidad han aumentado desde entonces, pero las peculiaridades que presenta la filosofía del siglo XVI y, quizás, una determinada manera de fijar los periodos históricos, siguen dando actualidad a las palabras del historiador inglés.

Sea como sea, y con relación a nuestro tema, recordemos que la edición príncipe del Aristóteles griego es la de Aldo Manuzio en Venecia, con fecha de 1495 hasta 1498. A partir de entonces aparecen diversas ediciones griegas y traducciones latinas que adolecen, en algunas ocasiones, de criterios historiográficos erróneos; es así como, por ejemplo, la edición latina de Iunta de 1550-2 en Venecia incluye entre los libros de Aristóteles obras como el Liber de Causis.

Como hemos apuntado, la lectura directa del texto, gracias a la invención de la imprenta y a la extensión del conocimiento de las lenguas clásicas, resulta accesible a un número mayor de personas que se hallan fuera del estamento eclesiástico-universitario. Pero estas personas disponen, además, de unos Comentarios a la Física de Aristóteles desconocidos durante la Edad Media, como son los de Alejandro de Afrodisia (s. II), Temistio (s. IV), Juan Filopón (s. VI) o Simplicio (s. VI), que se añaden a los ya conocidos de Boecio, Alberto Magno, Egidio, Tomás de Aquino, Escoto, Ockham, Marsilio; a los más recientes de Cayetano, Sonzinas, Juan de Jandun, Buridán, Zimara, Nifo, y a los Comentarios árabes de Avicena, Avempace, Alfarabí, Avenzoar, Averroes, etc. De este modo la lectura de Aristóteles da pie a un eclecticismo al que, por otra parte, siempre había favorecido.

Con todo, la enseñanza de la doctrina aristotélica seguía presente prácticamente en todas las universidades europeas, católicas y protestantes; Alcalá, Coimbra, Salamanca, París, Oxford, Tübingen o Wittemberg hubieran podido sus-

'Charles B. SCHMITT: Aristotle and the Renaissance. Cambridge MA/London, 1983, p. 22. Véanse, del mismo autor, otras obras relacionadas con nuestro tema: The Aristotelian Tradition and Renassaince Universities. London, 1984. - La tradizione aristotelica: fra Italia e Inghilterra. Bibliopolis. Napoli, 1985. - Reappraisals in Renaissance Thought. Variorum Reprints. London, 1989. 
cribir hasta muy entrado el siglo XVII las palabras de Julio César Scalígero en su Poética de 1561: "Aristoteles, imperator noster, omnium bonarum artium dictator perpetuus". Sin embargo, algunas singularidades nos avisan de los desplazamientos que se están dando.

Por una parte, en Italia, aunque en los Studia de las distintas órdenes religiosas se mantenían las disciplinas tradicionales y muchos de sus miembros redactaban intrascendentes comentarios ad usum alumnorum, en las universidades importantes no se daba mucho relieve al estudio de la Física y de la Metafísica, mientras que sobresalían Facultades de Medicina, Matemáticas y Derecho como las de Padua, Pisa y Bolonia. Médicos tan sobresalientes como Cardano, Fracastoro médico oficial del Concilio de Trento - Vesalio, el mismo Scalígero y, ya en el XVII, William Harvey, dan prueba de la vitalidad de la Escuela de Padua al tiempo que explican el interés preferente por el estudio de la naturaleza que mostrarán los pensadores italianos más importantes de esta época y el desprecio dirigido a toda investigación sobre la naturaleza que se base en la especulación, incluyendo en este juicio a la misma Física de Aristóteles. En este sentido escribirá Bernardino Telesio en el Proemio a su magna obra De Rerum Natura iuxta propria principia: "La construcción del mundo y la magnitud y naturaleza de los cuerpos contenidos en él no han de ser investigadas por la razón, como hacian los antiguos, sino que han de ser percibidas por los sentidos y sacadas de las cosas mismas". "Non ratio inquirenda sed sensu percipienda". ${ }^{2}$ Con un punto de ingenuidad, resuena en esta obra que se comenzó a publicar en 1565, el clamor que recorre el siglo XVI y que Francis Bacon interpretará correctamente en su Novum Organon: huir de la barbarie aristotélico-escolástica que usa, como dirá Hobbes, un lenguaje insignificante, y atenerse a los resultados que proporcione la aplicación de una lógica que parta de los hechos. La naturaleza de las cosas se investigará no ya a partir de unos criterios de autoridad, sino a partir de la capacidad del investigador en descubrir los principios según los cuales se rige la propia naturaleza. Incluso el escolástico español Benito Pereira (o Pererio), profesor del Colegio Romano, escribirá en el prólogo de su De Rerum naturalium Principiis: "Ego multum Platoni tribuo, plus Aristoteli, sed rationi plurimum".

Por otra parte, mientras se mantiene en las universidades la estructura tradicional del Trivium y el Quatrivium, en los Studia Humanitatis se enseñan la gramática, la retórica, la poética, la historia y la filosofía moral, a lo que la ratio studiorum de los jesuitas añadirá las matemáticas. Esto permite la incursión en ámbitos del saber que anteriormente no se cultivaban y la aparición de una actitud de responsabilidad individual en la investigación y el pensamiento. Sin embargo, digamos que el intento de sustituir la enciclopedia de las ciencias medievales no aparece hasta la publicación del De tradendis disciplinis de Luis Vives en 1531 y la de The Advance of Leaming de Lord Bacon de 1605.

2 BERBARDINO TELESIO: De Rerum Natura iuxta propia principia. A cura di Luigi de Franco. Vol. I. Casa del Libro. Cosenza, 1965, p. 26.

3 BENEDICTUS PEREIRA: De Communibus omnium rerum naturalium principiis et affectibus. Lugduni, 1588, Praefatio. 
Este clima vigoroso de renovación lleva a la aparición en Italia de dos corrientes aristotélicas: el llamado averroismo paduano y el alejandrinismo. El primero parece que no tuvo la importancia que después se le ha querido atribuir. Juan de Jandun, huyendo de los tribunales de París, llega a Padua de la mano de su amigo Marsilio y allí enseña su lectura averroista de Aristóteles y publica diversas obras. Le seguirá Paolo Véneto, un autor confuso y poco prolífico. El alejandrinismo, sin embargo, inspirado en el materialismo que expone Alejandro de Afrodisia en su Comentario a la Física, sí tiene amplia difusión y entre sus seguidores se cuentan Pietro Pomponazzi, Giacomo Zabarella, Cremonini, Cesalpino, Acquapendente, Fracastoro, etc. Hay que anotar que muchos de ellos - como el mismo Pomponazzi, Agostino Nifo, Zimara, etc. - mezclan el aristotelismo con el ocultismo, la astrología, el estoicismo o la revelación de Hermes Trimegisto.

Esta corriente naturalista genera la aparición de unos pensadores muy originales a los que Descartes en una carta a Mersenne llamará novatores y que son Bernardino Telesio, Francesco Patrizi, Giordano Bruno y Tommasso Campanella. De la misma manera que Maquiavelo habia introducido el naturalismo en política, estos filósofos lo introducirán en la física y abrirán el camino al naturalismo religioso que cultivarán los llamados libertinos, un colectivo que incluye nombres tan dispares como Vanini, Naudé, Diodati, Gassendi, La Mothe le Vayer, etc.

Al lado de estos aristotelismos novedosos y más bien eclécticos encontramos el aristotelismo escolástico cuyos más ilustres representantes son sobre todo los jesuitas españoles y portugueses que se agrupan bajo el denominativo común de segunda Escolástica y que incluyen el célebre Cursus Coninbricensis, dirigido por el padre Fonseca, las obras del cardenal Francisco de Toledo, las de Benito Pereira y las de Francisco Suárez. Todos estos autores se remiten a la doctrina de Santo Tomás de Aquino pero conocen y citan las obras de su tiempo y los avances de la ciencia mientras buscan un equilibrio que resulta ser a menudo ecléctico, como eclécticos habían sido en realidad los Comentarios de los escolásticos del XIII y el XIV.

Y ciertamente no podemos dejar de mencionar la corriente anti-aristotélica que atraviesa todo el siglo XVI - si bien arranca, siglo y medio antes, de los escritos de Petrarca - y que supone por parte de algunos autores una concienzuda lectura de las obras de Aristóteles, especialmente de la Physica. Sin embargo los ataques provienen no sólo del campo de la ciencia y la filosofía sino también del campo de las letras y la religión; podemos así recordar los escritos de Lorenzo Valla, del mismo Lutero, de Copérnico, de Petrus Ramus, de Bruno y Campanella, los cuales, junto a muchos otros, podríamos decir que desembocan en la nueva lógica de Lord Bacon mientras crean el clima que dará al antiaristotelismo una posición de prestigio intelectual en las obras de Galileo, Descartes o Hobbes.

\section{La lectura de la Physica}

A lo largo del siglo XVI la importancia de la Física crece en proporción al olvido en que cae la Metafísica. A esto lleva tanto el materialismo de los aristotélicos como el naturalismo de los anti-aristotélicos. El rechazo de la especulación que 
veíamos en Telesio es un rechazo a la especulación metafísica, aunque a menudo la comprensión de la doctrina aristotélica en este campo sea muy peculiar, como en la atribución de tres principios que son tres dioses hecha por Patrizi a la exposición del filósofo griego: "Aristóteles a este Dios uno y principio metafísico le añadió otro físico. El metafísico mueve como principio final, mientras que el Dios físico mueve como principio eficiente. Pero a éstos añadió un tercer Dios, aquél que no hace nada en vano con la Naturaleza". ${ }^{4}$ La afiliación neoplatónica de Patrizi podía haberle llevado a una mejor comprensión del sistema aristotélico a partir de este mismo triple principio que descubre en él, pero, siendo la lucha antiaristotélica una lucha básicamente ideológica contra el poder intelectual de la Iglesia, el ataque no puede admitir componendas, como no las admite Telesio al escribir: "Quienes antes que nosotros investigaron la construcción de este mundo y la naturaleza de las cosas que contiene, parece que no las comprendieron en absoluto". ${ }^{\circ}$

Encontramos un rastro de esta oposición entre Física y Metafísica en los mismos escolásticos. ${ }^{6}$ Por una parte vemos que Pereira - al que seguirá Suárez separará la Filosofía Primera como ciencia del ente en general, tanto físico como metafísico, de la Teología, ciencia que tiene como objeto exclusivo a Dios. Por otra parte, Toledo y otros muchos escolásticos distinguirán en Aristóteles la Física general, que trata de los principios y propiedades comunes a todos los entes corpóreos, y la Física especial, a la que pertenecen los tratados como el De Coelo, el De Generatione et Corruptione, etc. que tratan de los distintos fenómenos físicos. Este desplazamiento llevó a algunos como Mirandulano a afirmar que la Física de Aristóteles forma parte de la Filosofía Primera, sentencia que, aun siendo rechazada, es discutida por Pereira y los Conimbricenses. Este desplazamiento tiende a considerar la Metafísica y la misma Física General como un elenco de definiciones que fijen los significados de los términos generales como lugar, tiempo, movimiento, etc. que después serán usados en la Física Especial.

El panorama de los escritos sobre la Physica en el siglo XVI no es, sin embargo, homogéneo sino que es preciso distinguir entre ellos tres géneros diferentes. El primero es el de los manuales propiciados por la ratio studiorum de los jesuitas y otras órdenes religiosas que llevan a cabo una reducción a menudo pedestre de la doctrina aristotélica y a los que seguramente se refiere Patrizi cuando escribe que, siendo la física peripatética "tenebrosa, oscura, impía e incierta", sin embargo "nostro hoc saeculo, dum eius philosophia per compendiola et summulas publice docetur, recepta appellatur philosophia".

4 FRANCESCO PATRIZI DA CHERSO: Nova de Universis Philosophia. Emendationes. Leo S. Olschki Editore. Firenze, 1993, p. 31-2.

5 B. TELESIO: Ibidem, p. 26.

- Para el desarrollo de este punto nos basamos especialmente en la exposición de Cees LEIJENHORST en: Hobbes and the Aristotelians. The Aristotelian Setting of Hobbes's Natural Philosophy. Zeno. Institute of Philosophy. Utrecht, 1998, p. 19-51.

F. PATRIZI: Ibidem, p. 33 . 
El segundo género sería el que continúa la tradición de los grandes comentaristas y al que ya hemos hecho alusión al referimos a la Segunda Escolástica. ${ }^{8}$ Aparte del Curso de los Complutenses de la Orden carmelitana, serán los jesuitas quienes aportarán los Comentarios más sobresalientes a la Física de Aristóteles. Así Francisco de Toledo publica In octo libros de Physica auscultatione (1573) e In de generatione et corruptione (1575); Pereira escribirá su De communibus omnium rerum naturalium principiis et affeccionibus, libri quindecim (1588); el Cursus Philosophicus de los Coninbricenses, después de comentar los ocho libros de la Física (1591), presentará el comentario a los Parva Naturalia, al De Coelo, a los Meteorum, al De Generatione et Corruptione y al De Anima; y Suárez, aparte de su magnífico Comentario al De Anima (publicado en 1621 pero redactado en 1591), tratará diversas cuestiones de Física general en sus Disputationes metaphysicae (1597). El valor de estos comentarios está en la información enciclopédica que proporcionan al recoger las opiniones de los distintos comentaristas e incluso de los escritores de su tiempo, y en el esfuerzo riguroso por asumir en su horizonte filosófico la problemática que los avances de la ciencia iba suscitando.

$Y$ en tercer lugar debemos situar los nuevos tratados que, rompiendo con la tradición, quieren ofrecer una nueva visión y un nuevo tratamiento de las cuestiones ya planteadas por Aristóteles. Así Gerolamo Cardano, aparte de numerosas obras sobre matemáticas, medicina, física, astrología, etc. publica el De subtilitate (1550) y el De rerum varietate (1558); Pietro Pomponazzi escribe su De Naturalium Effectuum Causis sive de Incantationibus (1556); Agostino Nifo sus Comentarios a la Physica; Bernardino Telesio su De rerum natura iuxta propia principia (1586), y Francesco Patrizi su Nova de Universis Philosophia (1591); junto a éstas, las obras más conocidas de Giordano Bruno y de Tommasso Campanella rematarán medio siglo italiano de admirable y magnífica reflexión filosófica acerca de la Naturaleza, sus principios y sus fenómenos. Sus autores, hombres del Renacimiento, tendrán conciencia de ser los iniciadores de una nueva época y considerarán que, tras largos siglos de ignorancia, ellos aportan finalmente verdadera luz acerca del conocimiento de la realidad física. Y, ciertamente, ellos preparan el advenimiento de la nueva ciencia especialmente con su renovación del concepto de movimiento, de espacio y de tiempo: eliminada tanto la noción de "lugar natural" como el principio de inercia aristotélico, irán reduciendo todo cambio a movimiento y concebirán un espacio y un tiempo matemáticos cuya realidad será indiferente a que se dé o no en ellos movimiento alguno. De este modo, aun defendiendo muchos de ellos un cosmos vivo y animado, prepararán los instrumentos intelectuales aptos para el pleno desarrollo del mecanicismo.

Cfr. JOSÉ LUIS ABELLÁN: Histonia crítica del pensamiento español. 2: La Edad de Oro (siglo XVI). Espasa-Calpe. Madrid, 1979, p. 527-634. Véase también: CARLO GIACON: La seconda scolastica. 3 vol. Fratelli Bocca. Milano, 1943, 1946 y 1950; y las Historias de la Filosofía Española de Marcial Solana, Guillermo Fraile y Alain Guy. 